\title{
Medical Leadership: Doctors at the Helm of Change
}

\author{
Nicholas Chadi*
}

\section{INTRODUCTION}

Since the beginnings of the modern era, medicine has evolved tremendously. Merely two hundred years ago, American and European medical treatments were generally provided by independent physicians who went from home to home to offer their services. From this form of medicine, often referred to as "bedside medicine", (1) Western countries started to move towards a more centralized form of medical care provision: hospital medicine. During the 20th century, as cities steadily grew larger and more populated, numerous hospital supercomplexes with complicated hierarchal structures emerged. Employing hundreds and sometimes thousands of health care professionals, hospitals became increasingly difficult to manage and required the presence of a well organized management staff.

With the current aging of Western populations, developed countries now face major problems within their healthcare systems concerning economics and efficiency. Having to deal with the consequences of a strong movement of medicalization over the past few decades that has brought more and more elements of everyday life under medical jurisdiction, (2) Western governments are now struggling to restrain the rising costs of their national healthcare coverage. Seeking new venues and solutions, many countries like Canada allocate an increased importance to practices such as preventive medicine, surveillance medicine and homecare treatments. (1) All three of these practices tend to reduce the role played by hospitals in healthcare. However, hospital treatment remains an essential part of Western healthcare programs, and the development of parallel structures does not eliminate the management issues that health ministries are faced with.

\footnotetext{
*To whom correspondence should be addressed: Nicholas Chadi

441 Président Kennedy, Apt 1801

Montreal, QC, H3A 0A4

nicholas.chadi@mail.mcgill.ca
}

Within hospitals and clinics, many aspects of the physician's daily routine have changed dramatically during the past generation, adding another level of complexity to the management of healthcare. Both in Canada and abroad, doctors are increasingly unhappy with the way they are managed. A main cause of physician dissatisfaction lies in the fact that "the individual orientation that doctors were trained for does not fit with the demands of current healthcare systems." (3) Faced with numerous problems like "funding constraints [and] demand[s] for greater accountability for the safety, the quality and the efficacy of healthcare," (4) doctors are more and more frustrated with their daily workload and don't feel as appreciated and supported as they might have been in the past. Physicians frequently receive instructions regarding these new demands from leaders who either do not possess a clinical background or do not wish to occupy the leadership role they are occupying. Hence, the lack of clear and reassuring guidance coming from respected and qualified professionals affects doctors as much as the overall well-being of the whole Canadian medical system.

Striving to improve the efficiency of their healthcare systems, health ministries of countries such as Australia, the United Kingdom and Canada often hold hospital management teams accountable for the increases in healthcare spending. (5) In blaming hospitals, these countries uncover an ongoing problem that is causing more and more trouble to health ministers worldwide. In fact, Bruce Dowton, the Dean of Medicine at the University of New South Wales explains that "[d]espite leadership roles being critical, [Western governments] persist with outmoded models of organizations and pay inadequate attention to developing individual leaders and new models of leadership within the medical profession". (4) In other words, as Dowton suggests, hospital inefficiency could realistically be eliminated by training healthcare professionals adequately in the area of medical leadership. Thus, in order to face current and future changes in healthcare, Canada needs to develop a new 
generation of competent medical leaders involved at all levels of its healthcare system. Many countries worldwide are starting to acknowledge the numerous advantages of developing leadership skills in their medical students, physicians, CEOs/CMOs and health ministers. In Canada, although some promising initiatives have already been taken, much still needs to be done in order for the healthcare system to benefit from strong medical leadership.

\section{MEDICAL LEADERSHIP}

"Medical leadership" has only recently started to take its place as a common medical term. As Dowton noticed four years ago, "leadership has received little attention in [...] peer-reviewed medical literature." (4) By definition, medical leadership consists of having fully trained physicians occupying leadership roles relevant to the practice of medicine. Physician leadership can include resource managing, decision making, recruiting and medical consulting as well as implementing changes and improvements in hospital and clinical settings (6). Medical leadership also goes alongside with adequate team building activities and an appropriate sharing of decision power. (7) In this perspective, there is no room for an all powerful CEO (Chief Executive Officer) having nothing in common with the team he is leading. On the contrary, good medical leadership intrinsically depends on the acknowledgement of the important role of all the levels of healthcare workers involved in the functioning of a hospital. (7)

Countries around the world are starting to realize the importance of good medical leadership. Although Canada is slowly starting to recognize the importance of training good medical leaders, other countries like the Netherlands, Denmark and especially the United Kingdom are a step ahead in initiating a wave of changes inside their respective healthcare systems (8). In Great Britain, the National Healthcare Services (NHS) is well aware of the importance of training competent medical leaders. For example, in a recent public report, J. Clark and C.M. Morgan, two physicians working at the NHS headquarters, wrote that the improvement of the British healthcare system through the successful implementation of current and future medical reforms "is very dependent on the support and active engagement of all doctors, not only in their practitioner activities but also in their managerial and leadership roles". (9) Thus, British healthcare ministers understand that fully trained doctors must be involved in all the levels of the country's medical structure in order for optimal changes to take place.

Although coping with a very different healthcare system, American medical associations, governments and private healthcare consortiums also recognize the urgent need to involve physicians in all future medical reforms. Richard W. Schwartz, a physician working for the Kentucky College of Medicine who possesses an MBA, states that "precisely because they are at the center of clinical service and delivery, physicians are the ideal leaders for healthcare in the 21st century". (10) Hence, being the ones who are the most aware of the changes needed in national medical systems, physicians must not be swept aside in the implementation of measures that will directly affect their daily work.

Furthermore, the NHS has already taken concrete measures to implement good medical leadership in all levels of its medical structure. In fact, the same report cited above explains that in the UK, "there are some exciting medical management and leadership initiatives being introduced both locally and nationally in both undergraduate and postgraduate training" (9). Through its integrated approach to medical leadership, the UK brings forth the importance of developing good physician leadership at multiple levels.

Considering the similar challenges faced by both the British and Canadian healthcare systems, four different levels of Canadian healthcare medical professionals could strongly benefit from improved medical leadership: students, physicians, health executives and health ministers. In their respective scopes of activity, all four of these healthcare actors play an equally important role in solidifying Canada's medical hierarchy.

\section{MEDICAL STUDENTS: LEARNING TO BECOME MEDICAL LEADERS}

Currently, very little importance is given to medical leadership in Canadian medical curricula. Medical admission procedures, including individual interviews and autobiographical letters, focus mostly on uncovering qualities like empathy, determination and intelligence as well as skills that are used by physicians when practicing their traditional medical role. However, universities most certainly represent the best location to target, develop and train competent medical leaders for the future. In order to reach this goal, common leadership skills must be looked for in medical school applicants. In an article entitled "Physician Leadership," Dr. Woo explains that qualities like "vision, ability to sacrifice and courage" (11) represent skills that are mandatory for any leader and should not be forgotten when recruiting future doctors. While most common leadership skills might at first seem like essential assets for any good physician, some of them could be seen as conflicting with the qualities that are actually targeted by Canadian universities. For 
example, while a well-performing corporate leader must aim for profit and time efficiency, practising physicians must show empathy and care for their patients. For students wishing to become both good physicians and efficient leaders, the time-saving vs. quality of care duality represents a major dilemma. In the financially constrained reality of the Canadian healthcare system, this is a problem that every physician must cope with when undertaking new leadership roles. However, through the training they receive in medical school, doctors are taught to understand human nature like no other professionals. Considering this advantage, medical students should certainly be able to become both competent leaders and well estimated physicians if they are given the opportunity to develop the appropriate skills. Hence, if medical school applicants are to occupy leadership positions during their career, they must be chosen according to their leadership capacities. As for adequate leadership training, it must be integrated into medical curricula.

\section{PHYSICIANS: INTEGRATING GOOD MEDICAL LEADERSHIP IN EVERYDAY PRACTICE}

Physicians' professional activities require them to be good team leaders. In fact, doctors working in both clinics and hospitals lead small groups of healthcare professionals on a daily basis. While the teams they are responsible for might seem small, physicians nonetheless need to demonstrate essential leadership skills. When they work in a large hospital setting, they also have to be able to execute directions issued by their superiors appropriately to assure the fluidity of interstaff relationships and the well-being of the hospital's work environment. Thus, most doctors are constantly involved in situations where they need to both be able to manage and be managed. However, while physicians can be perceived as "smart individuals whose long-term vision sustained them through years of gruelling education" (12) this does not necessarily make them the best team leaders. To help them become the leaders they are well capable of becoming, Canadian health institutions must then strive to offer adequate continuous medical leadership training to their practicing doctors. In their leadership tasks, physicians must rely on three main qualities which form the basis of medical leadership: the capacity to work in teams, the ability to personify essential leadership skills and possession of a strong emotional capacity.

First, since the ability to work well in a team is not necessarily something that is readily teachable in schools, hospitals must seek to provide adequate training workshops to their physicians and implement measures that will allow them to feel more comfortable inside the existing leadership structure. For instance, healthcare institutions can seek to create physician advisory committees that include both management staff and physicians. This way, doctors can get more involved in the functioning of their hospital (7) Also, this would make it easier for them to create positive group dynamics in their own everyday leadership spheres.

Second, the NHS Medical Leadership Competency Framework suggests that all doctors should be able to excel in five different domains: "Personal qualities and professionalism, working with others, managing business, transforming services and setting directions." (13) While the first two skills are often mastered in medical school, the last three, being directly related to management and requiring practical experience, must be introduced to practicing physicians all through their career. Since very few doctors have the opportunity to complete an MBA, continuous education and training must take an important part in developing adequate medical leadership for active doctors.

Third, in order to become sensitive leaders, doctors must learn to master their emotional intelligence, also called "EQ". Including aspects like "self-awareness, self-management [and] social awareness" (12), emotional intelligence allows doctors to act as realistic and efficient leaders that can bring a larger contribution to their work team.

\section{HEALTH EXECUTIVES: CEO VS. CMO}

In order for hospitals to function efficiently, they need to be led by a strong and capable management team. In developed countries, very few Chief Executive Officers are from a clinical background and even fewer of them are medically qualified. While it would definitely be optimal for all hospitals to hire their directors among candidates issued from the medical field, it seems impossible in the short term. In the meantime, including empowered Chief Medical Officers (CMOs)practicing physicians - in all hospital management teams might prove to be a good alternative. Overall, the $\mathrm{CMO}$ can be seen as a facilitator who allows a better interaction between the hospital healthcare professionals and the management team. In other words, "The CMO generally has specific duties related to the management, direction and evaluation of quality initiatives and clinical affairs, but is increasingly involved with the strategic planning and relationships with critical physician groups." (8) In Canada, there are very few CMO positions available. Considering how much positive input they could bring to any large hospital, it is essential that Canadian ministries look into creating more $\mathrm{CMO}$ job opportunities. 


\section{MINISTERS OF HEALTH: A NEED FOR INSPIRATIONAL LEADERS}

For captains of well-run ships, it is essential to understand the tasks accomplished by all of their crew members. It is equally important for the heads of the Canadian ministries of health-both national and provincial-to be in tune with the professionals working under them. The present minister of health in the province of Quebec, Yves Bolduc, and his predecessor, Philippe Couillard, are both experienced physicians. However, having experienced physicians working as national or provincial Ministers of Health has not been the dominant pattern during recent decades. The same problem also prevails in many other developed countries; the Austrian Minister of Health Andrea Kdolsky was once a famous physician and is now at the head of one of the world's top performing healthcare systems, but the British, American and German Ministers of Health do not have any relevant clinical expertise. It is in the best interests of all parties involved that a healthcare professional himself or herself be at the helm of any healthcare system.

\section{CANADIAN HEALTHCARE: PROBLEMS AND SOLUTIONS}

In Canada, although fundamental problems regarding the implementation of strong medical leadership are still very present, many promising initiatives are starting to emerge. First, in its official publication of the 2005 CanMEDS standards, the Royal College of Physicians and Surgeons of Canada established a thorough description of the seven essential skills that should guide the practice of all Canadian physicians. Among the seven standards listed (all of equal importance), "manager" appears in the fourth position and is defined as such: "The CanMEDS Manager Role describes the active engagement of all physicians as integral participants in decision-making in the operation of the healthcare system." (14) While this might seem like a proof that Canada is now embracing a new movement towards better medical leadership, it has to be noted that CanMEDS standards only serve as guidelines for medical curricula and do not have any true legislative or reformative power.

Second, the Canadian Medical Association has recently started to offer intensive leadership programs and workshops through its Physician Manager Institute. Open to all physicians and medical students, the core leadership program which comprises five 3-day intensive sessions is described as the following: "Through these highly interactive workshops, [physicians] will learn how to lead and manage change, transfer best practices into action, inspire excellence and sustain productive relationships at all levels in [a] hospital or health organization" (15). Even though these workshops are easily accessible and offered all across Canada, they are fairly costly (close to $1500 \$$ per workshop) and aren't equally recognized in Canadian hospitals. Furthermore, very few incentives are provided to doctors or future doctors who consider pursuing this leadership training.

Third, medical programs in universities all around Canada are starting to offer the option of taking management classes as elective credits during the four years of formal medical education. Among Canadian universities, McGill is a pioneer in this domain. In 1996, McGill developed a joint MD-MBA program that is still unique in Canada. Aiming to train fully recognized physicians that will also acquire strong management training through the completion of a health-oriented MBA, this program is defined by the McGill Faculty of Medicine as "a five-year program that prepares graduating physicians for leadership positions in the health care sector." (16) Although it was originally meant to accept at least five students every year, only 2 students were admitted to the MD-MBA program in 2007 due to a very small number of applicants. This is a proof that much still needs to be done in order to attract more competent medical leaders.

Even though legitimate initiatives aiming to develop a new generation of medical leaders seem to be well initiated, many fundamental problems still affect the Canadian transition towards more comprehensive medical leadership. For example, in most hospitals, there is a huge and complex bureaucracy that revolves around hospital directors who are often disconnected with physicians' needs and requirements. As stated by Dowton, "in many settings, implementation of sound policy appears to be in danger of falling into a morass of hierarchically driven bureaucratese, involving a blame-prone audit driven by paper-based compliance." (4) While doctors should be the ones involved in implementing healthcare reforms, resolutions and concrete plans are left in the hands of bureaucrats who often fail in adequately communicating with the ones who will be leading the actual changes. This underlines an omnipresent duality that prevails between doctors and CEOs: physicians do not want to get involved with CEOs who don't truly understand their reality. Also, in the few cases where potent leadership positions are held by qualified physicians, management tasks are often seen as a punishment. For instance, in Canada, leadership positions are far from being valued by the medical society and the unfortunate physicians forced to assume them are often compelled to accept dramatic drops in their salary.

In addition, being a full-time medical manager is not usually considered a possible career path by medical 
school graduates. Since very few job opportunities allow fully trained doctors to both make use of their medical skills and act as respected medical leaders, it is very difficult for a doctor to commit to a full-time management career. (8) Furthermore, the few Canadian physician-leaders frequently can not take part in realizing the global vision of the hospital they are working for as they are working under health ministers or executives who most often are not associated with the medical profession. It is hence not very likely that doctors who have just completed up to 10 years of demanding medical training will accept to struggle in a work setting where their newly acquired competences aren't truly valued.

\section{CONCLUSION}

In conclusion, the Canadian medical system faces many new challenges that require ambitious health reforms. As many countries begin to realize the importance of good medical leadership, Canada must put an increased effort into developing a new generation of competent and efficient medical leaders. In doing such, Canadian health ministries must acknowledge the importance of training accomplished medical leaders at all levels of their healthcare structures: the student, the physician, the executive and the government official. Having already shown a certain number of promising initiatives related to the implementation of medical leadership, Canada must renew its efforts to overcome many fundamental problems that are still very present in the national healthcare system.

In order to give Canadian healthcare a more comprehensive and solidly led structure, many immediate measures can be envisioned. Among the different ways of improving national medical leadership, five suggestions particularly apply to the Canadian context: (i) offering an increased recognition to doctors undertaking leadership positions, (ii) offering higher wages and greater incentives to motivate future doctors to orient themselves towards health-related management careers (iii) selecting more medical students who have the ability to become great leaders (iv) integrating medical leadership training in all steps of medical education, and finally, (v) privileging the filling of medical leadership positions by managers who have a solid clinical background. Currently, Canada has one of the most comprehensive and inclusive healthcare systems in the world. Canada is also considered as one of the countries offering the best overall living conditions. (17) To keep its place as a global leader in terms of the quality of life it offers to its citizens, Canada must not hesitate to follow the path leading to solid and well sustainable medical leadership.

\section{REFERENCES}

1. Armstrong D. The rise of surveillance medicine. Sociology of health \& illness. 1995;17(3):393-404.

2. Conrad P. Medicalization and Social Control. Annual Review of Sociology. 1992;18(1):209-32.

3. Edwards N, Kornacki MJ, Silversin J. Unhappy doctors: what are the causes and what can be done? British Medical Journal. [serial online] 2002;324(7341):835. Available from: URL: http://www.bmj.com/cgi/content/extract/324/7341/835. Accessed March 8, 2008.

4. Dowton SB. Leadership in medicine: where are the leaders? Med J Aust. [serial online] 2004;181(11/12):[3 screens]. Available from: URL: http://www.mja.com.au/public/issues /181_11_061204/dow10543_fm.html. Accessed January 14, 2008.

5. Sullivan T, Baranek PM. First do no harm: making sense of the Canadian health reform. Vancouver: UBC press; 2003.

6. Edwards N, Kornacki MJ, Silversin J. Unhappy doctors: what are the causes and what can be done? British Medical Journal. [serial online] 2002;324(7341):835. Available from: URL: http://www.bmj.com/cgi/content/extract/324/7341/835. Accessed March 8, 2008.

7. Frank JR. Medical leadership and effective interprofessional health care teams: A competency-based approach. 2007;[11 screens]. Available at: URL: http://ambulance.nsw.gov.au/amwac/amwac/pdf/10_frank.pdf. Accessed February 21, 2008.

8. The imperative for medical leadership. 2005; [6 screens]. Available at: URL: http://www.ecgmc.com/insights_ideas $/$ pdfs/IN_Imperative_Medical_Leadership.pdf. Accessed February 21, 2008.

9. Clark J, Morgan DM. Improving the effectiveness of health services: The importance of generating greater medical engagement in leadership. 2007;[17 screens] Available at: URL: http://www.institute.nhs.uk/images/documents/BuildingCapabil ity/Medical_Leadership/scopingstudyreport110507.pdf. Accessed February 21, 2008.

10. Schwartz RW, Pogge C. Physician leadership: essential skills in a changing environment. The American Journal of Surgery [serial online] 2000;180(3):[6 screens]. Available from: URL: http://www.sciencedirect.com/science?_ob=MImg\&_imagekey $=$ B $6 \mathrm{VH} \mathrm{S}-41 \mathrm{~N} \mathrm{~K} 86 \mathrm{~K}-9-5 \& \_\mathrm{cd} \mathrm{i}=6074 \&$ user $=458507 \&$ orig $=$ search \&_coverDate $=09 \% 2 \mathrm{~F} 30 \% 2 \mathrm{~F} 2000$ \&_sk $=998199996 \& \mathrm{view}=\mathrm{c} \& \mathrm{wchp}=\mathrm{dGLbVtb}-$ zSkWW\&md5=29543c3200e2d1892e 1 f95e62e4c526c\&ie=/sda rticle.pdf. Accessed January 24, 2008.

11. Kt W. Physician leadership. Singapore Med J [serial online] 2007;48(12):[5 screens]. Available at: URL: http://smj.sma.org.sg/4812/4812s11.pdf. Accessed January 14, 2008.

12. Serio CD, Epperly T. Physician Leadership: A New Model for a New Generation. Family Practice management [serial online] 2006 Feb;13(2):[5 screens]. Available at: URL: http://www.aafp.org/fpm/20060200/51phys.html. Accessed January 14, 2008.

13. Medical leadership competency framework. 2008;[7 screens]. Available at: URL: http://www.institute.nhs.uk/images/ documents/BuildingCapability/Medical_Leadership/medical\%2 0leadership\%20comp\%20framework.pdf. Accessed February 21, 2008.

14. CanMEDS 2005 Framework. 2005;[9 screens] Available at: URL:http://meds.queensu.ca/medicine/obgyn/pdf/CanMEDS_2 005_Framework.pdf. Accessed February 21, 2008.

15. Canadian Medical Association. Leadership Development Workshops. 2007; [24 screens] Available at: URL: 
https://cma.ca/multimedia/CMA/Content_Images/Inside_cma/L eadership/2008/PMI/PMI_Brochure2008.pdf. Accessed March 9th, 2008

16. McGill Faculty of Medicine. Programs and Degrees. 2007[1 screen] Available at:

URL:

https://home.mcgill.ca/medicine/admissions/programsanddegre es/. Accessed March 9th, 2008.
17. Prescott RA. The Wellbeing of Nations: A Country-by-Country index of Quality of Life and the Environment. Washington D.C.: Island Press; 2001.

Nicholas Chadi (M.D.C.M. 2012) has served as a junior editor for the MJM over the past year. He is currently a medical student at McGill University. 